\title{
Psychometric properties of PTSD Checklist in sample of male veterans
}

\author{
Stefanie M. Keen, PhD; ${ }^{1-2}$ Catherine J. Kutter, PhD; ${ }^{1}$ Barbara L. Niles, PhD; ${ }^{1-2 *}$ Karen E. Krinsley, PhD $^{1-2}$ \\ ${ }^{1}$ National Center for Posttraumatic Stress Disorder, Department of Veterans Affairs Boston Healthcare System, \\ Boston, MA; ${ }^{2}$ Boston University School of Medicine, Boston, MA
}

\begin{abstract}
The psychometric properties of the PTSD Checklist (PCL) were investigated in a sample of treatment-seeking and community-dwelling male veterans. In conjunction with previous reports, results from the present study indicate that the PCL possesses strong, robust psychometric properties. The current investigation suggests a cutoff score of 60 -higher than previous investigations-related to posttraumatic stress disorder (PTSD) diagnosis derived from the Clinician-Administered PTSD Scale. This research supports the use of the PCL as a brief self-report measure of PTSD symptomatology.
\end{abstract}

Key words: Clinician-Administered PTSD Scale, Combat Exposure Scale, Evaluation of Lifetime Stressors, mental health symtomatology, PCL, potentially traumatic event, psychometric validation, PTSD, rehabilitation, self-report measure, veterans.

\section{INTRODUCTION}

Since its introduction in 1993, the PTSD Checklist (PCL) has been widely used in research and clinical settings. The original validation study [1] was presented at the annual meeting of the International Society for Traumatic Stress Studies but was never published, potentially limiting its accessibility to individuals wanting to use or accurately cite the instrument. In the present study, we replicated Weathers et al.'s investigation [1] in a sample of male veterans similar to that used in their initial validation. Furthermore, the current validation of the PCL is based on the diagnostic criteria outlined in the Diagnostic and Statistical Manual of Mental Disorders-Fourth Edition (DSMIV) [2], whereas Weathers et al. [1] used the DSM-Third Edition-Revised (DSM-III-R) criteria [3].
The PCL is a 17-item self-report measure of posttraumatic stress disorder (PTSD) symptomatology. Respondents indicate the extent to which they have been bothered by each symptom in the past month using fivepoint Likert scales with anchors ranging from "Not at all" to "Extremely." Different scoring procedures may be used to yield either a continuous measure of PTSD symptom severity or a dichotomous indicator of diagnostic status. Dichotomous scoring methods include either an overall cutoff score or a symptom cluster scoring approach. The symptom cluster scoring method corresponds to the DSMIV diagnostic criteria [2], typically requiring a score of 3 ("Moderately") or greater on one cluster B symptom (reexperiencing), three cluster $\mathrm{C}$ symptoms (avoidance/numbing), and two cluster D symptoms (hyperarousal). Currently two versions of the PCL exist: a military version, in which

\footnotetext{
Abbreviations: CAPS = Clinician-Administered PTSD Scale, CES = Combat Exposure Scale, DSM-III-R = Diagnostic and Statistical Manual of Mental Disorders-Third Edition-Revised, DSM-IV = DSM-Fourth Edition, ELS = Evaluation of Lifetime Stressors, ELS-I = ELS interview, ELS-Q = ELS self-report questionnaire, Mississippi Scale $=$ Mississippi Scale for Combat-Related PTSD, NPV = negative predictive value, PCL = PTSD Checklist, $\mathrm{PPV}=$ positive predictive value, $\mathrm{PTE}=$ potentially traumatic event, PTSD = posttraumatic stress disorder, $\mathrm{SD}=$ standard deviation, VA = Department of Veterans Affairs.

${ }^{*}$ Address all correspondence to Barbara L. Niles, PhD; National Center for PTSD (116-B-2), VA Boston Healthcare System, 150 S. Huntington Ave, Boston, MA 02130; 857364-4128; fax: 857-364-4501. Email: Barbara.Niles@va.gov DOI: $10.1682 / J R R D .2007 .09 .0138$
} 
reexperiencing and avoidance symptoms apply to militaryrelated stressful experiences only, and a civilian version, in which reexperiencing and avoidance symptoms apply to any stressful experience. In addition, a number of researchers have developed and used study-specific versions of the PCL, in which reexperiencing and avoidance symptoms apply to a stressful experience (e.g., sexual assault, motor vehicle accident) that is specified by the experimenters.

In the original validation study of an earlier version of the PCL, Weathers et al. examined the psychometric properties of the PCL in veterans of the Vietnam and gulf wars [1]. Their findings are summarized in Table 1, along with

Table 1.

Previous reports on psychometric properties of PCL.

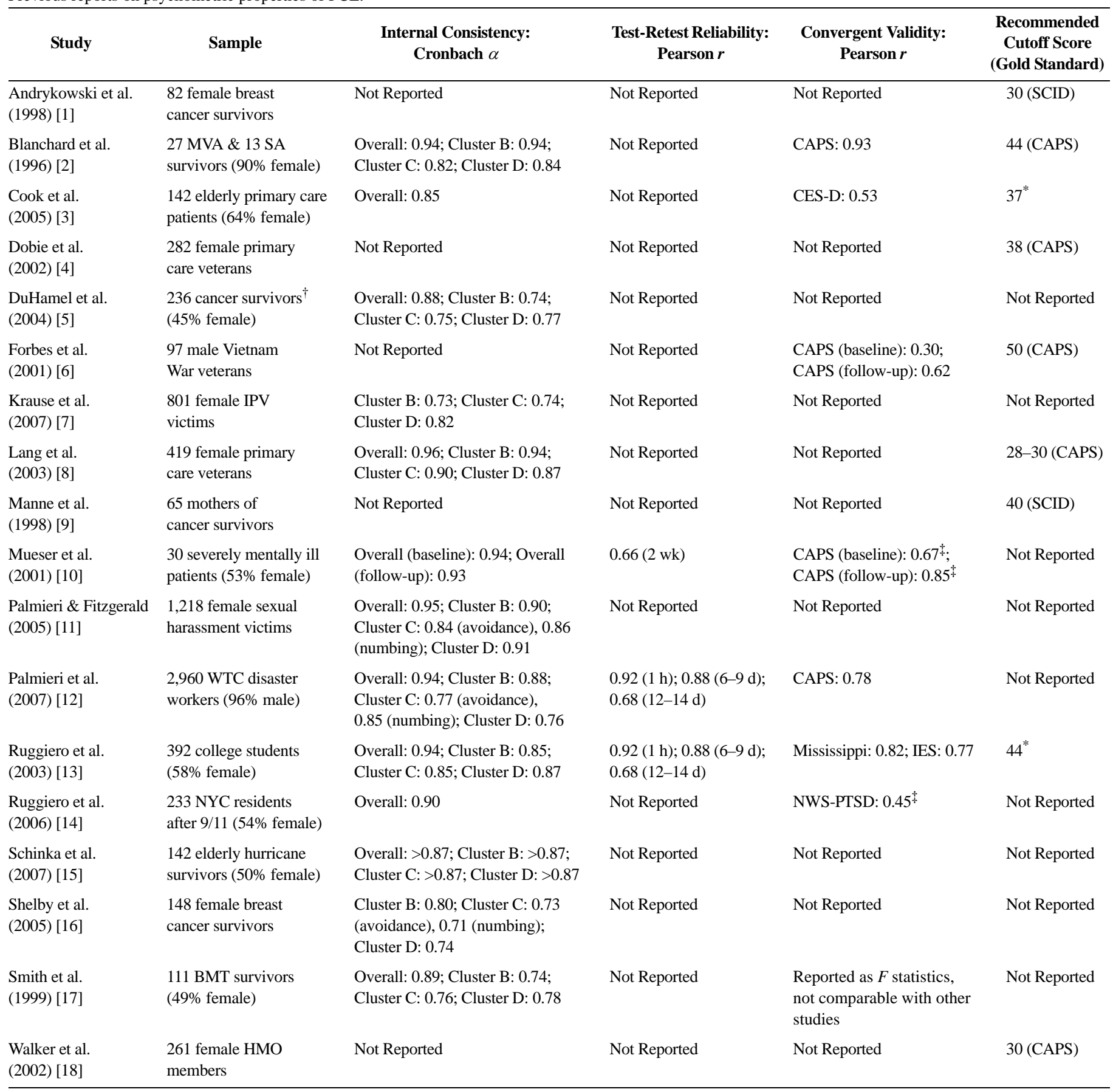


Table 1. (Continued)

Previous reports on psychometric properties of PCL.

\begin{tabular}{|c|c|c|c|c|c|}
\hline Study & Sample & $\begin{array}{l}\text { Internal Consistency: } \\
\text { Cronbach } \alpha\end{array}$ & $\begin{array}{c}\text { Test-Retest Reliability: } \\
\text { Pearson } r\end{array}$ & $\begin{array}{l}\text { Convergent Validity: } \\
\text { Pearson } r\end{array}$ & $\begin{array}{l}\text { Recommended } \\
\text { Cutoff Score } \\
\text { (Gold Standard) }\end{array}$ \\
\hline $\begin{array}{l}\text { Weathers et al. } \\
\text { (1993, Study 1) [19] }\end{array}$ & $\begin{array}{l}123 \text { male Vietnam } \\
\text { war veterans }\end{array}$ & $\begin{array}{l}\text { Overall: 0.97; Cluster B: 0.93; } \\
\text { Cluster C: 0.92; Cluster D: } 0.92\end{array}$ & $0.96(2-3 \mathrm{~d})$ & $\begin{array}{l}\text { Mississippi: 0.93; Pk Scale: } \\
\text { 0.77; IES: 0.90; CES: } 0.46\end{array}$ & 50 (SCID) \\
\hline $\begin{array}{l}\text { Weathers et al. } \\
\text { (1993, Study 2) [19] }\end{array}$ & $\begin{array}{l}1,006 \text { gulf war } \\
\text { veterans ( } 88 \% \text { male) }\end{array}$ & $\begin{array}{l}\text { Overall: 0.96; Cluster B: 0.90; } \\
\text { Cluster C: 0.89; Cluster D: } 0.91\end{array}$ & Not Reported & Mississippi: 0.85 & Not Reported \\
\hline $\begin{array}{l}\text { Yeager et al. } \\
\text { (2007) [20] }\end{array}$ & $\begin{array}{l}840 \text { primary care } \\
\text { veterans ( } 79 \% \text { male) }\end{array}$ & Not Reported & Not Reported & Not Reported & 31 (CAPS) \\
\hline
\end{tabular}

1. Andrykowski MA, Cordova MJ, Studts JL, Miller TW. Posttraumatic stress disorder after treatment for breast cancer: Prevalence of diagnosis and use of the PTSD Checklist-Civilian Version (PCL-C) as a screening instrument. J Consult Clin Psychol. 1998;66(3):586-90. [PMID: 9642900]

2. Blanchard EB, Jones-Alexander J, Buckley TC, Forneris CA. Psychometric properties of the PTSD Checklist (PCL). Behav Res Ther. 1996;34(8):669-73. [PMID: 8870294]

3. Cook JM, Elhai JD, Areán PA. Psychometric properties of the PTSD Checklist with older primary care patients. J Trauma Stress. 2005;18(4):371-76. [PMID: 16281234]

4. Dobie DJ, Kivlahan DR, Maynard C, Bush KR, McFall M, Epler AJ, Bradley KA. Screening for post-traumatic stress disorder in female Veteran's Affairs patients: Validation of the PTSD Checklist. Gen Hosp Psychiatry. 2002;24(6):367-74. [PMID: 12490337]

5. DuHamel KN, Ostroff J, Ashman T, Winkel G, Mundy EA, Keane TM, Morasco BJ, Vickberg SM, Hurley K, Burkhalter J, Chhabra R, Scigliano E, Papadopoulos E, Moskowitz C, Redd W. Construct validity of the posttraumatic stress disorder checklist in cancer survivors: Analyses based on two samples. Psychol Assess. 2004;16(3):225-66. [PMID: 15456381]

6. Forbes D, Creamer M, Biddle D. The validity of the PTSD checklist as a measure of symptomatic change in combat-related PTSD. Behav Res Ther. 2001; 39(8):977-86. [PMID: 11480838]

7. Krause ED, Kaltman S, Goodman LA, Dutton MA. Longitudinal factor structure of posttraumatic stress symptoms related to intimate partner violence. Psychol Assess. 2007;19(2):165-75. [PMID: 17563198]

8. Lang AJ, Laffaye C, Satz LE, Dresselhaus TR, Stein MB. Sensitivity and specificity of the PTSD checklist in detecting PTSD in female veterans in primary care. J Trauma Stress. 2003;16(3):257-64. [PMID: 12816338]

9. Manne SL, Du Hamel K, Gallelli K, Sorgen K, Redd WH. Posttraumatic stress disorder among mothers of pediatric cancer survivors: Diagnosis, comorbidity, and utility of the PTSD checklist as a screening instrument. J Pediatr Psychol. 1998;23(6):357-66. [PMID: 9824924]

10. Mueser KT, Salyers MP, Rosenberg SD, Ford JD, Fox L, Carty P. Psychometric evaluation of trauma and posttraumatic stress disorder assessments in persons with severe mental illness. Psychol Assess. 2001;13(1):110-17. [PMID: 11281032]

11. Palmieri PA, Fitzgerald LF. Confirmatory factor analysis of posttraumatic stress symptoms in sexually harassed women. J Trauma Stress. 2005;18(6):657-66. [PMID: 16382424]

12. Palmieri PA, Weathers FW, Difede J, King DW. Confirmatory factor analysis of the PTSD Checklist and the Clinician-Administered PTSD Scale in disaster workers exposed to the World Trade Center Ground Zero. J Abnorm Psychol. 2007;116(2):329-41. [PMID: 17516765]

13. Ruggiero KJ, Del Ben K, Scotti JR, Rabalais AE. Psychometric properties of the PTSD Checklist-Civilian Version. J Trauma Stress. 2003;16(5):495-502. [PMID: 14584634$]$

14. Ruggiero KJ, Rheingold AA, Resnick HS, Kilpatrick DG, Galea S. Comparison of two widely used PTSD-screening instruments: Implications for public mental health planning. J Trauma Stress. 2006;19(5):699-707. [PMID: 17075907]

15. Schinka JA, Brown LM, Borenstein AR, Mortimer JA. Confirmatory factor analysis of the PTSD checklist in the elderly. J Trauma Stress. 2007;20(3):281-89. [PMID: 17597125]

16. Shelby RA, Golden-Kreutz DM, Andersen BL. Mismatch of posttraumatic stress disorder (PTSD) symptoms and DSM-IV symptom clusters in a cancer sample: Exploratory factor analysis of the PTSD Checklist-Civilian Version. J Trauma Stress. 2005;18(4):347-57. [PMID: 16281232]

17. Smith MY, Redd W, DuHamel K, Vickberg SJ, Ricketts P. Validation of the PTSD Checklist-Civilian Version in survivors of bone marrow transplantation. J Trauma Stress. 1999;12(3):485-99. [PMID: 10467557]

18. Walker EA, Newman E, Dobie DJ, Ciechanowski P, Katon W. Validation of the PTSD Checklist in an HMO sample of women. Gen Hosp Psychiatry. 2002; 24(6):375-80. [PMID: 12490338]

19. Weathers FW, Litz BT, Herman DS, Huska JA, Keane TM. The PTSD Checklist (PCL): Reliability, validity, and diagnostic utility. In: Proceedings of the Annual Conference of the International Society for Traumatic Stress Studies; 1993 Oct 25; San Antonio, Texas.

20. Yeager DE, Magruder KM, Knapp RG, Nicholas JS, Frueh BC. Performance characteristics of the posttraumatic stress disorder checklist and SPAN in Veterans Affairs primary care settings. Gen Hosp Psychiatry. 2007;29(4):294-301. [PMID: 17591505]

* Diagnostic utility based on PCL algorithm-derived/total scale scores, no gold standard comparison.

${ }^{\dagger}$ Includes 110 participants from Smith et al. [17].

${ }^{\ddagger}$ Convergent validity measured by Cohen $\kappa$.

BMT = bone marrow transplant, CAPS = Clinician-Administered PTSD Scale, CES = Combat Exposure Scale, CES-D = Center for Epidemiologic Studies Depression Scale, HMO = health maintenance organization, IES = Impact of Event Scale, IPV = intimate partner violence, Mississippi = Mississippi Scale for CombatRelated PTSD, MVA = motor vehicle accident, NWS-PTSD = National Women's Study PTSD Module, NYC = New York City, PCL $=$ PTSD Checklist, Pk $=$ Keane PTSD Scale of the Minnesota Multiphasic Personality Inventory-II, PTSD = posttraumatic stress disorder, SA = sexual assault, SCID = Structured Clinical Interview for Diagnostic and Statistical Manual of Mental Disorders, WTC = World Trade Center. 
19 other reports. Since the introduction of the PCL, additional studies have evaluated its psychometric properties [4-5] and examined its utility as a screening instrument for PTSD symptoms within specific clinical populations [6-7]. The findings from these studies, summarized in Table 1, offer strong evidence for the reliability and validity of the PCL within the samples investigated. Taken together, these studies support the utility of the PCL as a brief self-report screening instrument to assess for the presence of PTSD symptoms.

\section{Different Cutoff Scores Across Samples}

One discrepancy that has been noted across studies concerns the optimally efficient cutoff score for differentiating people with and without PTSD. Weathers et al. reported that a cutoff score of 50 optimized specificity and sensitivity of the PCL in their sample of Vietnam and gulf war veterans [1]. The majority of subsequent studies, however, have suggested that lower cutoff scores more accurately identify individuals with PTSD (Table 1).

Noting their lower optimal cutoff score of 44 in a sample that was mostly female and recently exposed to a potentially traumatic event (PTE), Blanchard et al. suggested that gender and/or time since a PTE may influence reporting style, resulting in different optimal cutoff scores across samples [4]. Others have suggested that factors such as severity of PTE exposure and treatmentseeking status may be associated with these differences [8]. However, given the lack of studies using diverse and/ or mixed samples to test these hypotheses, definitively answering these questions is not possible at this point.

The determination of the most appropriate cutoff depends not only on the clinical population but also on the goals of the assessment. For example, a lower cutoff score may be preferable in situations in which the goal is to identify all possible cases of PTSD (e.g., for clinical screening purposes), while a higher cutoff score may be more appropriate when excluding individuals who do not meet criteria for PTSD is important (e.g., for research purposes).

\section{Present Study}

The present study addresses several deficiencies and limitations in the PCL research literature. As illustrated in Table 1, while several studies have reported on various psychometric properties of the PCL, clearly none has conducted as thorough an investigation as the unpublished Weathers et al. study [1], which included measures of internal consistency, test-retest reliability, convergent validity, comparison to a gold standard, and factor struc- ture. In the present study, we address these limitations by providing a more comprehensive investigation of the psychometric properties of the PCL in a sample of male veterans. Furthermore, we suggest that the utility of the PCL be considered within the context of the assessment environment, including clinical settings, research studies, and veteran-based compensation and pension evaluations.

\section{METHODS}

\section{Participants}

Participants were 114 male veterans who had participated in a larger study conducted at the National Center for PTSD in the Department of Veterans Affairs (VA) Boston Healthcare System [9]. Participants were recruited from the VA Boston Healthcare System and from the surrounding New England community via newspaper advertisements and posted flyers. All data were collected at the National Center for PTSD. At the time of their enrollment, participants were informed that the purpose of the study was to develop more accurate and reliable psychological evaluations for lifetime stressors. We included both treatmentseeking veterans and individuals recruited from the community in an effort to increase variability with respect to PTE exposure and mental health symptomatology (see Table 2 for a breakdown of PTEs by event type). Potential participants were excluded if they were actively psychotic, suicidal, homicidal, or unable to refrain from substance use for 24 hours before and during the study. Participants ranged in age from 29 to 65 years (mean \pm standard deviation [SD] $=47.4 \pm 7.1)$. Twenty-five participants (21.9\%) met the diagnostic criteria for PTSD. Additional demographic information is presented in Table 3 . An additional 10 participants did not complete the protocol, failing to return for the second and/or third session; therefore, their data were excluded from all analyses.

Table 2.

Participants' self-report of exposure to potentially traumatic events $(N=114)$.

\begin{tabular}{lrrrrrr}
\hline \multirow{2}{*}{ Event Type } & \multicolumn{2}{c}{ Childhood } & & \multicolumn{2}{c}{ Adulthood } \\
\cline { 2 - 3 } \cline { 6 - 7 } & \multicolumn{1}{c}{$\boldsymbol{n}$} & $\mathbf{\%}$ & & $\boldsymbol{n}$ & $\mathbf{9}$ \\
\hline Physical Abuse or Assault & 54 & 47.4 & & 55 & 48.2 \\
Sexual Abuse or Assault & 17 & 14.9 & & 9 & 7.9 \\
Natural Disaster & 36 & 31.6 & & 28 & 24.6 \\
War Zone Exposure & 0 & 0.0 & & 74 & 64.9 \\
Serious Illness or Injury & 47 & 41.2 & & 68 & 58.8 \\
Accident & 48 & 42.1 & & 53 & 46.5 \\
\hline \hline
\end{tabular}


Table 3.

Participant demographics $(N=114)$.

\begin{tabular}{|c|c|c|}
\hline Variable & $n$ & $\%$ \\
\hline \multicolumn{3}{|l|}{ Race/Ethnicity } \\
\hline Caucasian & 95 & 83.3 \\
\hline African American & 12 & 10.5 \\
\hline Other & 7 & 6.2 \\
\hline \multicolumn{3}{|l|}{ Level of Education } \\
\hline Did Not Complete High School & 3 & 2.7 \\
\hline High School/General Equivalency Diploma & 31 & 27.2 \\
\hline Some College & 48 & 42.1 \\
\hline Bachelor’s Degree or Higher & 32 & 28.1 \\
\hline \multicolumn{3}{|l|}{ Marital Status } \\
\hline Single & 28 & 24.6 \\
\hline Married/Living With Partner & 47 & 41.2 \\
\hline Separated/Divorced & 37 & 32.5 \\
\hline Widowed & 2 & 1.8 \\
\hline Currently Employed* & 40 & 35.4 \\
\hline \multicolumn{3}{|l|}{ Income $(\$)^{*}$} \\
\hline$<10,000$ & 38 & 33.6 \\
\hline $10,000-20,000$ & 27 & 23.9 \\
\hline $20,000-30,000$ & 20 & 17.7 \\
\hline$>30,000$ & 28 & 24.7 \\
\hline
\end{tabular}

\section{Measures}

Participants completed the PCL (civilian version) to ensure the applicability of items to both combat and noncombat PTEs. In accordance with the initial development and validation of the PCL, participants' responses were not based on a specific PTE. In addition, they completed the measures of PTE exposure and PTSD symptoms outlined in the following sections. In general, very few values were missing in this data set. Specifically, regarding the PCL data, only 2 of 1,938 data points were coded as missing. These 2 missing values were excluded from the computation of summary statistics used for later analysis. As a general guideline, instruments were included in analyses if less than 10 percent of the items were missing.

\section{Evaluation of Lifetime Stressors}

The Evaluation of Lifetime Stressors (ELS) is a multimethod protocol that uses both self-report questionnaire (ELS-Q) and interview (ELS-I) components to assess lifetime PTE exposure [9]. The ELS-Q is a 53-item screening questionnaire that assesses a variety of PTEs. The interviewer follows up all nonnegative responses on the ELSQ with specific probe questions from the ELS-I.

\section{Clinician-Administered PTSD Scale}

The Clinician-Administered PTSD Scale (CAPS) is a structured clinical interview that measures the frequency and intensity of the 17 PTSD symptoms [10] outlined in the DSM-IV [2]. Each symptom is assessed on a 5-point Likert scale, with higher scores indicating more severe PTSD symptoms. In addition, a dichotomous scoring system can be used to indicate whether or not a respondent meets the diagnostic threshold for PTSD. The present study used the "Frequency $>1$ /Intensity $>2$ " scoring rule, in which an item is considered to meet the threshold for a PTSD symptom when its frequency is rated as 1 or higher and its intensity as 2 or higher. This was the original scoring rule proposed by Blake et al. [10] and is commonly used in research and clinical settings. The CAPS has repeatedly demonstrated strong and robust psychometric properties and is considered the current gold standard for PTSD diagnosis [11-12].

\section{Mississippi Scale for Combat-Related PTSD}

The Mississippi Scale for Combat-Related PTSD (Mississippi Scale) is a brief self-report measure that assesses the presence and severity of PTSD symptoms and associated features [13]. This instrument, composed of 35 items measured on a 5-point Likert scale, is widely used with veteran populations and has demonstrated strong psychometric properties [13]. The Mississippi Scale has three versions: a military version referring specifically to military-related PTEs; a civilian version referring to any type of PTE; and a collateral version, in which a partner or significant other reports on the individual's symptoms. In the present study, we used the civilian version of the Mississippi Scale to ensure the applicability of items to either civilian or military PTEs. In accordance with the development and typical use of this instrument, participants were not instructed to complete it with a specific PTE in mind.

\section{Combat Exposure Scale}

The Combat Exposure Scale (CES) is a widely used self-report measure that assesses the intensity of combat exposure [14]. Standard scoring on the CES yields a weighted sum of seven items, each rated on a 5-point Likert scale, with higher CES total scores suggesting more severe combat exposure. This measure has demonstrated adequate psychometric properties [14]. 


\section{Procedure}

Data were collected over the course of three sessions within a 1-week interval. The self-report measures (PCL, Mississippi Scale, and CES) were completed during the initial session, the ELS was administered during the second and third sessions, and the CAPS was completed during the third session.

Participants provided informed consent at the time of enrollment in the initial study, and their data were archived with all identifying information removed. After obtaining approval from the institutional review board of the VA Boston Healthcare System, we analyzed these deidentified data to replicate and extend previous research on the psychometric properties and validity of the PCL.

\section{RESULTS}

Based on data from the ELS interviews, results indicated that participants reported from 2 to 24 lifetime PTEs (mean $\pm \mathrm{SD}=11.1 \pm 5.3$ ), ranging from 0 to 13 childhood PTE types (mean $\pm \mathrm{SD}=4.8 \pm 3.0$ ) and 1 to 13 adulthood PTE types (mean $\pm \mathrm{SD}=6.3 \pm 3.1$ ). Additional information with respect to PTE-type exposure is presented in Table 2. PCL scores ranged from 17 to 71 (mean \pm SD $=$
$33.0 \pm 15.5$ ) for individuals without PTSD and from 26 to 81 (mean \pm SD $=57.0 \pm 15.9$ ) for those with PTSD. An independent samples $t$-test revealed a significant difference between mean PCL scores for those with and without a PTSD diagnosis $(t(112)=6.83, p<0.001)$. Additionally, CAPS scores ranged from 0 to 59 (mean \pm SD $=13.4 \pm$ 15.4) for individuals without PTSD and from 47 to 108 (mean $\pm \mathrm{SD}=73.1 \pm 16.4$ ) for those with PTSD.

\section{Internal Consistency}

Internal consistency (coefficient $\alpha$ ) was 0.94 for cluster B symptoms, 0.91 for cluster C symptoms, 0.92 for cluster D symptoms, and 0.96 for the full scale. Table 4 outlines the item-scale correlations.

\section{Convergent Validity}

Convergent validity was demonstrated by strong correlations between the PCL and other measures of PTSD symptom severity. The PCL correlated strongly with total PTSD symptom severity on the CAPS ( $r=0.79, n=114$, $p<0.001)$ and with the Mississippi Scale $(r=0.90, n=$ $76, p<0.001)$. For the participants who were combat veterans (64.9\%), the PCL also demonstrated a strong relationship with the CES ( $r=0.62, n=74, p<0.001)$.

Table 4.

Item-scale correlations $(p<0.001)$ for PTSD Checklist (civilian version).

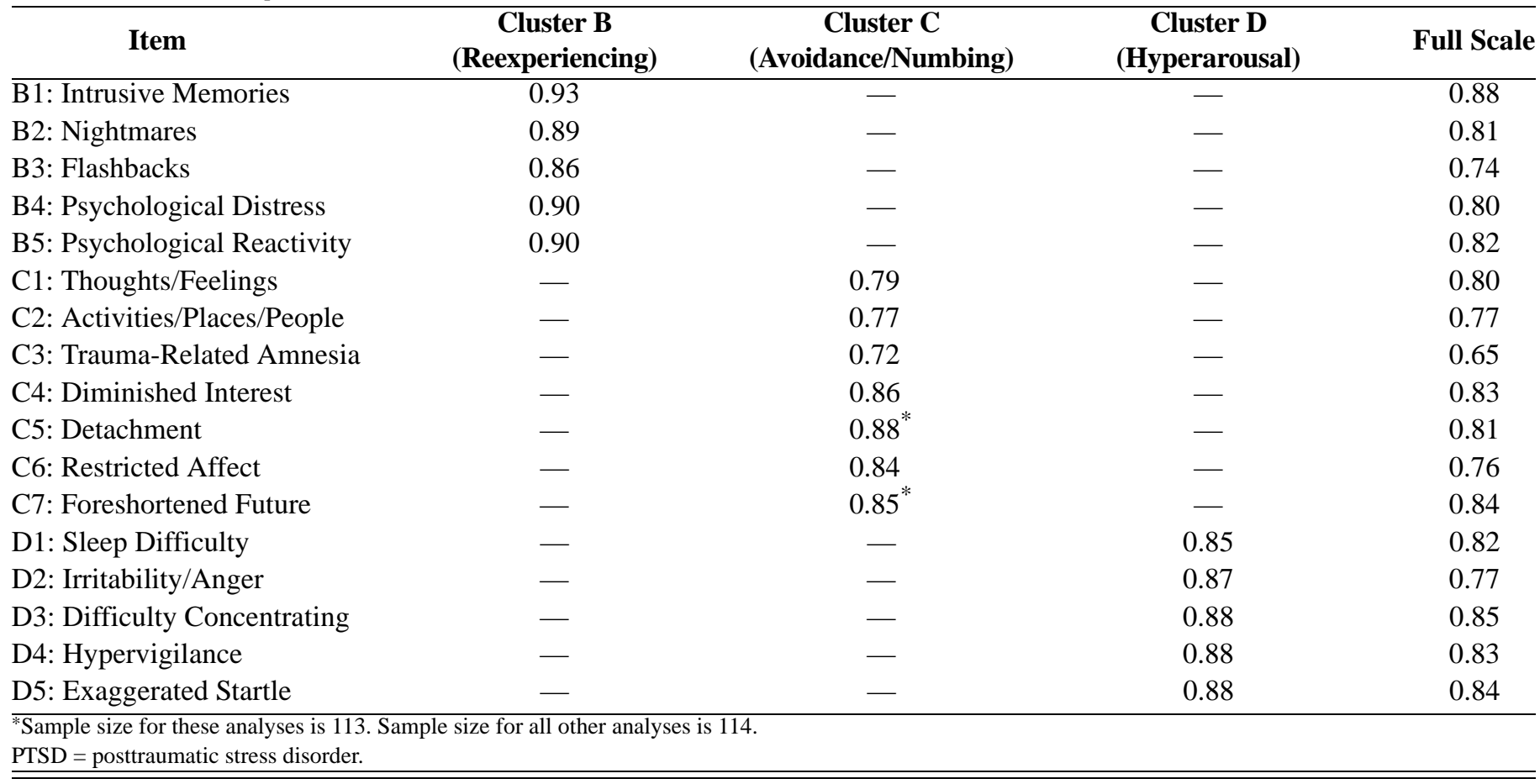




\section{Diagnostic Utility}

A receiver operator characteristic curve is a graphical representation of the trade-off between sensitivity (the probability that a condition that is present will be detected) and specificity (the probability that a condition that is absent will not be detected). The Figure shows the false positive rate ( 1 - specificity) on the $x$-axis and the true positive rate (sensitivity) on the $y$-axis. Values near the upper left corner of the curve maximize both sensitivity and specificity. The area under the curve is a measure of the overall accuracy, with a larger area (i.e., a maximum of 1.00) indicating more accuracy. For the PCL, the area under the curve was 0.86 .

We examined PCL scores in the range of 43 to 71 , using CAPS PTSD diagnosis as the criterion measure. We examined three measures of diagnostic value: sensitivity, specificity, and diagnostic efficiency (the proportion of cases correctly diagnosed). These values are presented in Table 5. The optimally efficient cutoff score was 60 , which yielded a sensitivity of 0.56 , a specificity of 0.92 , and a diagnostic efficiency of 0.84 .

We further investigated the diagnostic utility of the PCL by examining sensitivity, specificity, positive predictive value (PPV), negative predictive value (NPV), and diagnostic efficiency in relation to CAPS diagnosis based on two different scoring procedures (i.e., optimal cutoff score of 60 and symptom cluster scoring). Results indicated an advantage in sensitivity for the symptom cluster scoring method ( 0.72 for symptom cluster scoring vs 0.56 for optimal cutoff score) and an advantage in specificity for the cutoff score method (0.92 for optimal cutoff score vs 0.79 for symptom cluster scoring). For the cutoff score method, the PPV was 67 percent and the NPV was 88 percent. For the symptom cluster scoring method, the PPV was 49 percent and the NPV was 91 percent. Diagnostic efficiency was slightly better for the cutoff score method ( 0.84 for optimal cutoff score vs 0.77 for symptom cluster scoring) and was not improved by using a double-rule scoring procedure (i.e., cutoff score, then symptom cluster scoring).

\section{DISCUSSION}

The PCL is an easily administered self-report measure for assessing the 17 symptoms of PTSD outlined in the DSM-IV [2]. The present findings are similar to those

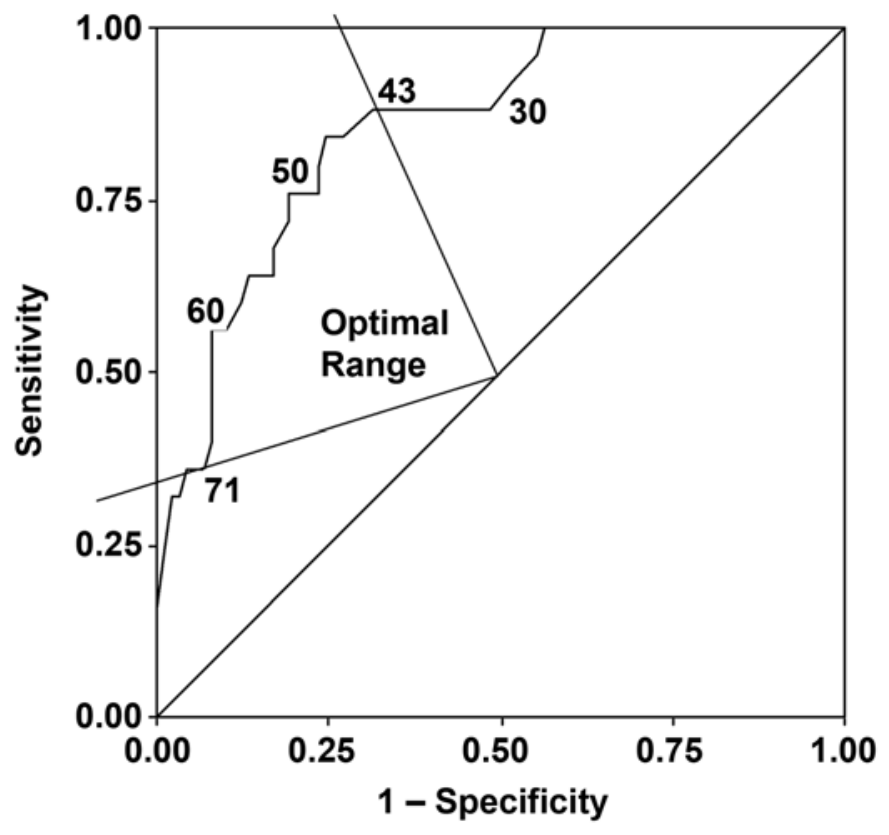

Figure.

Receiver operator characteristic curve depicting sensitivity and specificity of PTSD Checklist in identifying individuals meeting diagnostic criteria for posttraumatic stress disorder (PTSD).

reported by Weathers et al. [1], providing additional support for the PCL as a valid measure of PTSD symptomatology. Our findings of high internal consistency for groups of items corresponding to the DSM-IV symptom clusters are generally consistent with the current diagnostic structure of PTSD, although it is important to note that the item-scale correlations for cluster $\mathrm{C}$ are the weakest of the three symptom clusters. This finding may lend support to research suggesting that the avoidance and numbing symptoms of cluster C are more distinct than they are similar [15-18]. Strong correlations with other measures of PTSD (i.e., Mississippi Scale and CAPS) support the convergent validity of the PCL. Lastly, measures of diagnostic value support the accuracy of the PCL in relation to interview-derived diagnosis. Altogether, these findings support the use of the PCL as a brief measure of PTSD symptomatology.

When used as a continuous measure of PTSD symptom severity, the PCL demonstrated good diagnostic utility in this sample. The optimal cutoff score identified in the present study is higher than those reported in previous studies $[1,4]$, which may be explained by study-specific sample characteristics, the low base rate of PTSD (21.9\%) observed in the present study, diagnostic changes from DSM-III-R to DSM-IV, or differences in PTE exposure. 
JRRD, Volume 45, Number 3, 2008

Table 5.

Sensitivity, specificity, and accuracy of potentially optimal PTSD Checklist (civilian version) cutoff scores in identifying individuals with PTSD ( $N=$ 114). Optimally efficient cutoff was 60 (shown in bold).

\begin{tabular}{|c|c|c|c|c|c|c|}
\hline Cutoff & Sensitivity & Specificity & Efficiency & $\begin{array}{c}\text { No. (\%) } \\
\text { Correctly Classified }\end{array}$ & $\begin{array}{c}\text { False } \\
\text { Negatives }\end{array}$ & $\begin{array}{c}\text { False } \\
\text { Positives }\end{array}$ \\
\hline 43 & 0.76 & 0.76 & 0.76 & 87 (76) & 6 & 21 \\
\hline 45 & 0.76 & 0.77 & 0.77 & 88 (77) & 6 & 20 \\
\hline 47 & 0.76 & 0.79 & 0.78 & 89 (78) & 6 & 19 \\
\hline 48 & 0.76 & 0.81 & 0.80 & $91(80)$ & 6 & 17 \\
\hline 50 & 0.72 & 0.81 & 0.79 & 90 (79) & 7 & 17 \\
\hline 52 & 0.68 & 0.83 & 0.80 & $91(80)$ & 8 & 15 \\
\hline 53 & 0.64 & 0.83 & 0.79 & 90 (79) & 9 & 15 \\
\hline 54 & 0.64 & 0.84 & 0.80 & $91(80)$ & 9 & 14 \\
\hline 55 & 0.64 & 0.85 & 0.81 & $92(81)$ & 9 & 13 \\
\hline 56 & 0.64 & 0.86 & 0.82 & 93 (82) & 9 & 12 \\
\hline 57 & 0.60 & 0.88 & 0.82 & $93(82)$ & 10 & 11 \\
\hline 58 & 0.56 & 0.90 & 0.82 & $94(82)$ & 11 & 9 \\
\hline 59 & 0.56 & 0.91 & 0.83 & 95 (83) & 11 & 8 \\
\hline 60 & 0.56 & 0.92 & 0.84 & 96 (84) & 11 & 7 \\
\hline 61 & 0.52 & 0.92 & 0.83 & 95 (83) & 12 & 7 \\
\hline 62 & 0.48 & 0.92 & 0.83 & 95 (83) & 12 & 7 \\
\hline 63 & 0.44 & 0.92 & 0.82 & $93(82)$ & 14 & 7 \\
\hline 64 & 0.40 & 0.92 & 0.81 & $92(81)$ & 15 & 7 \\
\hline 65 & 0.36 & 0.93 & 0.81 & $92(81)$ & 16 & 6 \\
\hline 66 & 0.36 & 0.94 & 0.82 & $93(82)$ & 16 & 5 \\
\hline 67 & 0.36 & 0.95 & 0.82 & $94(82)$ & 16 & 4 \\
\hline 68 & 0.32 & 0.97 & 0.82 & $94(82)$ & 17 & 3 \\
\hline 69 & 0.32 & 0.98 & 0.83 & 95 (83) & 17 & 2 \\
\hline 71 & 0.24 & 0.99 & 0.82 & $94(82)$ & 19 & 1 \\
\hline
\end{tabular}

Note: Sensitivity = true positives/(true positives + false negatives). Specificity = true negatives/(true negatives + false positives). Diagnostic efficiency $=$ (true positives + true negatives)/total sample size.

PTSD = posttraumatic stress disorder.

Most participants in this study reported exposure to multiple PTEs (e.g., childhood abuse, natural disaster, and combat). Carlson suggested that such individuals may respond very differently to self-report measures of posttraumatic symptomatology than do individuals exposed to a single potentially traumatic episode/event [19]. While the extent of PTE exposure typically has not been reported in psychometric investigations, differences in the extent of PTE exposure may account for the higher cutoff score observed in the present investigation. Participants' self-report of symptomatic distress may be influenced by exposure to multiple PTEs, as reflected by the high levels of symptom reporting among participants both with and without PTSD. The relationship between this complex symptom picture and increased severity in reports of symptomatic distress likely contributes to the higher optimal cutoff score observed in the present study. This relationship may be further explained by the nature of the PCL, which does not typically require respondents to nominate a specific PTE for symptom endorsement. Instead, the PCL score for a person having experienced multiple PTEs is possibly influenced by symptoms related to wholly different events (e.g., memory deficits associated with child abuse and hypervigilance associated with combat exposure), which may lead to higher overall scores relative to individuals with single episode/event exposure.

The present findings generally support the use of either dichotomous scoring procedure (i.e., cutoff score 
vs symptom cluster scoring). Of note, however, is the trade-off between sensitivity versus specificity depending on the method used. While symptom cluster scoring yielded higher sensitivity, the cutoff score approach yielded higher specificity. Consistent with Clarke and McKenzie's conclusion [20], our findings suggest that the decision about which scoring method to use depends on the goals of the assessment. Symptom cluster scoring, which is associated with higher sensitivity and lower rates of false negatives, may be preferable for clinical screening, where the goal is to identify all possible cases of PTSD. The optimal cutoff score of 60 suggested by this study is associated with higher specificity and lower rates of false positives and may be preferable for research purposes when excluding all noncases is desirable. However, clinicians and researchers may choose alternate cutoff scores to meet their specific needs. For example, using a slightly lower cutoff score could possibly increase sensitivity, thereby improving the PCL's utility for screening.

While the present study possesses many strengths, several limitations should be addressed. First, the sample was a relatively small convenience sample restricted to male veterans; however, the consistency of our findings with those reported in other samples [4-5] supports the robustness of these findings. Second, although this study includes information on reliability, validity, and diagnostic efficiency, we do not have data on test-retest reliability. Other investigators have, however, documented adequate test-retest reliability over a 2-week time frame [1,5,21]. Third, results of the current study indicate that participants with and without PTSD reported broad and overlapping ranges of PCL scores, suggesting the possibility for a high false positive rate. However, the optimal cutoff of 60 accurately classified 84 percent of veterans in this sample, resulting in 7 false positive (6\%) and 11 false negative (10\%) diagnoses.

These results demonstrate the utility of the PCL as a screening tool for both clinical and research purposes. In addition to using the PCL in more straightforward clinical and/or research settings, we recommend using the PCL for veteran-based compensation and pension evaluations. According to a recent Institute of Medicine report on PTSD compensation and military service [22], the number of people receiving compensation for PTSD has increased significantly in recent years. Furthermore, this number is anticipated to continue to grow as veterans from Operations Iraqi Freedom and Enduring Freedom enter the veteran benefits system. Therefore, the need to develop an effective and efficient evaluation process for benefits services is paramount, especially with respect to assigning PTSD diagnosis and determining symptom severity. Given the advantages of the PCL with respect to ease of administration, flexible scoring, and psychometric soundness, the PCL would be highly useful as a standard screening component for a more thorough clinical evaluation of PTSD symptomatology.

While the CAPS is often used as a gold standard comparison in studies of psychometric validation, one should note that the CAPS and PCL measure different aspects of posttraumatic symptomatology. That is, while the CAPS assesses the frequency and intensity of PTSD symptoms, the PCL asks individuals to rate the degree to which they are "bothered" by their symptoms. An additional caveat pertains to the accuracy of classification: although the PCL accurately classified the majority of participants as either positive or negative for PTSD, a number of individuals were categorized incorrectly on the basis of their PCL scores. While the PCL is psychometrically sound as an indicator of PTSD symptomatology, it was not designed as a diagnostic instrument and should not be solely relied upon for diagnostic determinations.

\section{CONCLUSIONS}

The present investigation advances the current state of knowledge regarding the psychometric properties of the PCL. This study is more comprehensive than previous studies in its analysis of the reliability, validity, and diagnostic utility of the PCL. The validation of the PCL against the gold standard CAPS also represents a strength relative to some previous validation studies. The PCL is a useful instrument for research and can play a valuable role in screening and identifying candidates in need of a more thorough PTSD evaluation; however, we agree with Keane et al.'s recommendation for a multimodal approach to the assessment and diagnosis of PTSD [23].

\section{ACKNOWLEDGMENTS}

Stefanie M. Keen is now with the Department of Psychology, University of South Carolina Upstate, Spartanburg, South Carolina. Catherine J. Kutter is now with the White River Junction VA Medical Center and Dartmouth Medical School, White River Junction, Vermont. 
This material was based on work supported by the National Institute of Mental Heath (grant 2T32MH019836) and the Behavioral Sciences Division of the National Center for PTSD.

The authors have declared that no competing interests exist.

\section{REFERENCES}

1. Weathers FW, Litz BT, Herman DS, Huska JA, Keane TM. The PTSD Checklist (PCL): Reliability, validity, and diagnostic utility. In: Proceedings of the Annual Conference of the International Society for Traumatic Stress Studies; 1993 Oct 25; San Antonio, Texas.

2. American Psychiatric Association. Diagnostic and statistical manual of mental disorders: DSM-IV. 4th ed. Washington (DC): American Psychiatric Association; 1994.

3. American Psychiatric Association. Diagnostic and statistical manual of mental disorders: DSM-III-R. 3rd ed rev. Washington (DC): American Psychiatric Association; 1987.

4. Blanchard EB, Jones-Alexander J, Buckley TC, Forneris CA. Psychometric properties of the PTSD Checklist (PCL). Behav Res Ther. 1996;34(8):669-73. [PMID: 8870294]

5. Ruggiero KJ, Del Ben K, Scotti JR, Rabalais AE. Psychometric properties of the PTSD Checklist-Civilian Version. J Trauma Stress. 2003;16(5):495-502. [PMID: 14584634]

6. Andrykowski MA, Cordova MJ, Studts JL, Miller TW. Posttraumatic stress disorder after treatment for breast cancer: Prevalence of diagnosis and use of the PTSD ChecklistCivilian Version (PCL-C) as a screening instrument. J Consult Clin Psychol. 1998;66(3):586-90. [PMID: 9642900$]$

7. Walker EA, Newman E, Dobie DJ, Ciechanowski P, Katon $\mathrm{W}$. Validation of the PTSD checklist in an HMO sample of women. Gen Hosp Psychiatry. 2002;24(6):375-80. [PMID: 12490338]

8. Manne SL, DuHamel K, Gallelli K, Sorgen K, Redd WH. Posttraumatic stress disorder among mothers of pediatric cancer survivors: Diagnosis, comorbidity, and utility of the PTSD checklist as a screening instrument. J Pediatr Psychol. 1998;23(6):357-66. [PMID: 9824924]

9. Krinsley KE, Gallagher JG, Weathers FW, Kutter CJ, Kaloupek DG. Consistency of retrospective reporting about exposure to traumatic events. J Trauma Stress. 2003;16(4): 399-409. [PMID: 12895023]

10. Blake DD, Weathers FW, Nagy LM, Kaloupek G, Klauminzer G, Charney DS, Keane T. A clinician rating scale for assessing current and lifetime PTSD: The CAPS-1. Behav Therapist. 1990;18:187-88.

11. Blake DD, Weathers FW, Nagy LM, Kaloupek DG, Gusman FD, Charney DS, Keane TM. The development of a Clini-
cian-Administered PTSD Scale. J Trauma Stress. 1995;8(1): 75-90. [PMID: 7712061]

12. Weathers FW, Keane TM, Davidson JR. Clinicianadministered PTSD scale: A review of the first ten years of research. Depress Anxiety. 2001;13(3):132-56.

[PMID: 11387733]

13. Keane TM, Caddell JM, Taylor KL. Mississippi Scale for Combat-Related Posttraumatic Stress Disorder: Three studies in reliability and validity. J Consult Clin Psychol. 1988; 56(1):85-90. [PMID: 3346454]

14. Keane TM, Fairbank JA, Caddell JM, Taylor KL, Mora CA. Clinical evaluation of a measure to assess combat exposure. Psychol Assess. 1989;1:53-55.

15. Asmundson GJ, Wright KD, McCreary DR, Pedlar D. Posttraumatic stress disorder symptoms in United Nations peacekeepers: An examination of factor structure in peacekeepers with and without chronic pain. Cogn Behav Ther. 2003;32(1):26-37. [PMID: 16291532]

16. Buckley TC, Blanchard EB, Hickling EJ. A confirmatory factor analysis of posttraumatic stress symptoms. Behav Res Ther. 1998;36(11):1091-99. [PMID: 9737061]

17. King DW, Leskin GA, King LA, Weathers FW. Confirmatory factor analysis of the Clinician-Administered PTSD Scale: Evidence for the dimensionality of posttraumatic stress disorder. Psychol Assess. 1998;10(2):90-96.

18. Taylor S, Kuch K, Koch WJ, Crockett DJ, Passey G. The structure of posttraumatic stress symptoms. J Abnorm Psychol. 1998;107(1):154-60. [PMID: 9505048]

19. Carlson EB. Psychometric study of a brief screen for PTSD: Assessing the impact of multiple traumatic events. Assessment. 2001;8(4):431-41. [PMID: 11785587]

20. Clarke DM, McKenzie DP. A caution on the use of cutpoints applied to screening instruments or diagnostic criteria. J Psychiatr Res. 1994;28(2):185-88. [PMID: 7932280]

21. Mueser KT, Salyers MP, Rosenberg SD, Ford JD, Fox L, Carty P. Psychometric evaluation of trauma and posttraumatic stress disorder assessments in persons with severe mental illness. Psychol Assess. 2001;13(1):110-17. [PMID: 11281032]

22. Institute of Medicine and National Research Council. PTSD compensation and military service. Washington (DC): The National Academies Press; 2007.

23. Keane TM, Weathers FW, Foa EB. Diagnosis and assessment. In: Foa EB, Keane TM, Friedman MJ, editors. Effective treatments for PTSD: Practice guidelines from the International Society for Traumatic Stress Studies. New York (NY): The Guilford Press; 2000. p. 18-36.

Submitted for publication September 7, 2007. Accepted in revised form December 28, 2007. 